Keiichi Ohta, DDS

Department of Dentistry and Oral Surgery, Unit of Sensory and Locomotor Medicine, Division of Medicine, Faculty of Medical

Sciences, University of Fukui, Fukui, Japan
Hitoshi Yoshimura, DDS, PhD

Department of Dentistry and Oral Surgery,

Unit of Sensory and Locomotor Medicine,

Division of Medicine, Faculty of Medical

Sciences, University of Fukui, Fukui, Japan

\title{
Fibrous epulis: A tumorlike gingival lesion
}

A 40-YEAR-OLD WOMAN presented with a 1 -year history of an enlarging mass on the maxillary gingiva. The mass had been resected 4 years ago but had grown back. She said that she was otherwise in good health.

Examination revealed a nodule-wellcircumscribed, smooth, elastic, hard, measuring $20 \mathrm{~mm}$ by $18 \mathrm{~mm}$ - on the left maxillary anterior gingiva (Figure 1). In addition, the left maxillary second incisor was hypermobile, with poor-quality dental restorations. Examination of the neck found no cervical lymphadenopathy.

Computed tomography showed a welldemarcated, rim-enhanced soft-tissue mass in the left maxillary anterior gingiva with slight bone resorption at the left maxillary second incisor (Figure 2).

Biopsy was performed, and histopathologic study revealed keratinized epithelium overlying fibrous connective tissue with infiltration of inflammatory cells.

Based on these findings, we diagnosed recurrent fibrous epulis, resected the nodule, and extracted the loose tooth. At follow-up 20 months later there was no evidence of recurrence.

\section{CLINICAL RECOGNITION AND DIAGNOSIS}

Fibrous epulis, a type of inflammatory fibrous hyperplasia of the gingiva, is a relatively common tumorlike lesion. ${ }^{1,2}$ The possible origin is the periosteum and the periodontal ligament. ${ }^{1,2}$ Factors that lead to its development are local irritations such as poor-quality dental restorations, dental plaque, and calculus., ${ }^{2,3}$

The estimated prevalence of fibrous epulis is $0.09 \%$. It occurs at a wide range of ages and in women more often than men. ${ }^{4}$ Most lesions doi:10.3949/ccjm.88a.20127

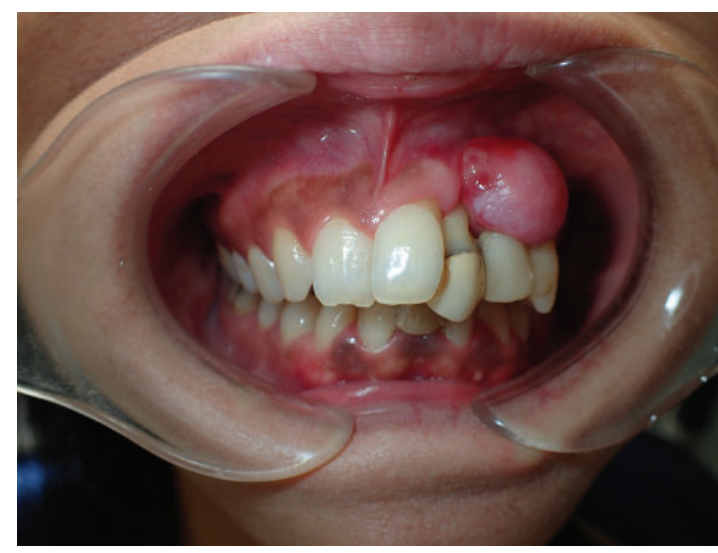

Figure 1. A well-circumscribed, smoothsurfaced, elastic, hard nodule, $20 \mathrm{~mm}$ by 18 $\mathrm{mm}$, on the left maxillary anterior gingiva.

occur on the maxillary anterior interdental papilla. ${ }^{1,2,4}$

Clinically, fibrous epulis is an asymptomatic, exophytic, smooth-surfaced or focally ulcerated, mucosal-colored mass with a variable growth rate. ${ }^{2,3}$ At presentation, most lesions are $10 \mathrm{~mm}$ to $20 \mathrm{~mm}$ in diameter; those that are large or grow rapidly tend to be misdiagnosed as neoplastic.,3

On computed tomography, lesions appear as a soft-tissue mass in the gingiva with mild enhancement, and up to one-third contain calcifications that can be easily seen. ${ }^{1,3}$ These calcified lesions are termed mineralizing fibrous epulis or peripheral ossifying fibroma. ${ }^{1}$ Bone resorption is relatively uncommon. ${ }^{5}$

Histologically, fibrous epulis shows hyperplastic epithelium that overlies fibrous connective tissue. ${ }^{1}$ Mineralized tissue, if present, consists of trabeculae or droplike metaplastic bone. ${ }^{1}$ 

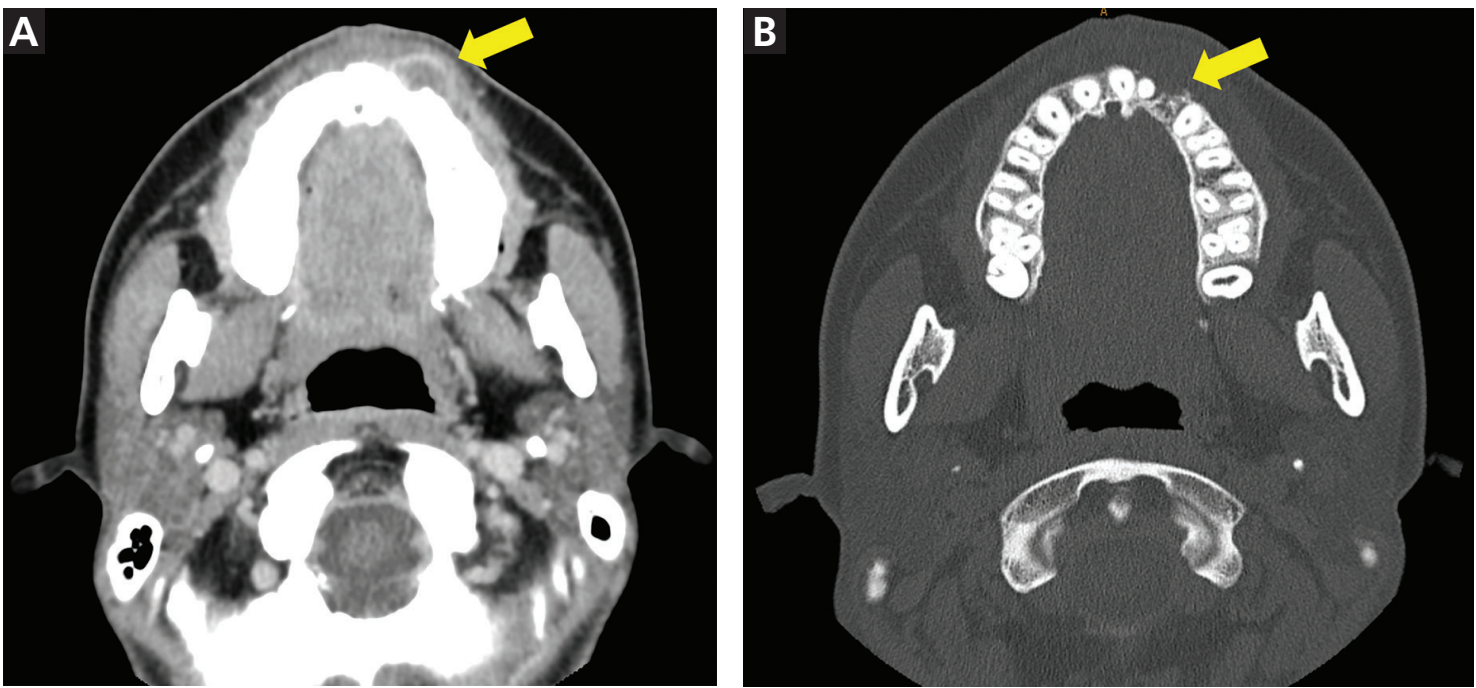

Figure 2. Computed tomography shows a well-demarcated, rim-enhanced soft tissue mass in the left maxillary anterior gingiva ( $A$, arrow), with slight bone resorption at the left maxillary second incisor (B, arrow).

The differential diagnosis includes pyogenic granuloma, peripheral giant cell granuloma, fibroma, peripheral odontogenic fibroma, fibrosarcoma, and squamous cell carcinoma. ${ }^{1,3,5}$ A slowly growing mass on the interdental papilla with local irritations and calcifications

The mass, resected

4 years ago, had grown back detected by computed tomography should raise suspicion of fibrous epulis. ${ }^{3}$ However, distinguishing fibrous epulis from the other conditions listed above may be difficult, and thus, histopathologic study is crucial. ${ }^{2,3}$

\section{REFERENCES}

1. Brierley DJ, Crane H, Hunter KD. Lumps and bumps of the gingiva: a pathological miscellany. Head Neck Pathol 2019; 13(1):103-113. doi:10.1007/s12105-019-01000-w

2. Fonseca GM, Fonseca RM, Cantín M. Massive fibrous epulis-a case report of a 10-year-old lesion. Int J Oral Sci 2014; 6(3):182-184. doi:10.1038/ijos.2013.75

3. Moon WJ, Choi SY, Chung EC, Kwon KH, Chae SW. Peripheral ossifying fibroma in the oral cavity: $\mathrm{CT}$ and $\mathrm{MR}$ findings. Dentomaxillofac Radiol 2007; 36(3):180-182 doi:10.1259/dmfr/59377498

4. Shulman JD, Beach MM, Rivera-Hidalgo F. The preva-

\section{TREATMENT}

Complete excision and curettage of the lesion is the preferred treatment because the recurrence rate is high, from $7 \%$ to $45 \% .^{3}$ Therefore, long-term follow-up is essential. Tooth extraction is not indicated unless there is underlying bone resorption.

\section{DISCLOSURES}

The authors report no relevant financial relationships which, in the context of their contributions, could be perceived as a potential conflict of interest.

lence of oral mucosal lesions in US adults: data from the Third National Health and Nutrition Examination Survey, 1988-1994. J Am Dent Assoc 2004; 135(9):1279-1286. doi:10.14219/jada.archive.2004.0403

5. Singh D, Pranab A, Mishra N, Sharma AK, Kumar S, Gupta P. Epulis_commonly misdiagnosed entity: a report of 2 cases. J Interdiscipl Med Dent Sci 2018, 6(2):2 doi:10.4172/2376-032X.1000230

Address: Keiichi Ohta, DDS, Department of Dentistry and Oral Surgery, Unit of Sensory and Locomotor Medicine, Division of Medicine, Faculty of Medical Sciences, University of Fukui, 233 Matsuokashimoaizuki, Eiheiji, Fukui 9101193, Japan; kohta@g.u-fukui.ac.jp 